\title{
Erratum to: Measuring and imaging nanomechanical motion with laser light
}

\author{
Andreas Barg $^{1} \cdot$ Yeghishe Tsaturyan $^{1} \cdot$ Erik Belhage $^{1} \cdot$ William H. P. Nielsen $^{1} \cdot$ \\ Christoffer B. Møller ${ }^{1} \cdot$ Albert Schliesser $^{1}$ (I)
}

Published online: 11 April 2017

(C) Springer-Verlag Berlin Heidelberg 2017

\section{Erratum to: Appl. Phys. B (2017) 123:8 \\ DOI 10.1007/s00340-016-6585-7}

The article "Measuring and imaging nanomechanical motion with laser light", written by Andreas Barg, Yeghishe Tsaturyan, Erik Belhage, William H. P. Nielsen, Christoffer B. Møller, Albert Schliesser was originally published Online First without open access. After publication in volume 123, issue 1, article ID 8, the authors decided to opt for Open Choice and to make the article an open access publication. Therefore, the copyright of the article has been changed to (C) The Author(s) [2017] and the article is forthwith distributed under the terms of the Creative Commons Attribution-Non Commercial 4.0 International License (http://creativecommons.org/licenses/by-nc/4.0/), which permits any non-commercial use, duplication, adaptation, distribution and reproduction in any medium or format, as long as you give appropriate credit to the original author(s) and the source, a link is provided to the Creative Commons license and any changes made are indicated.

The online version of the original article can be found under doi:10.1007/s00340-016-6585-7.

Albert Schliesser

albert.schliesser@nbi.dk

1 Niels Bohr Institute, Blegdamsvej 17, 2100 Copenhagen, Denmark 